\title{
Omics of probiotic bacteria: which features to seek?
}

\author{
L. Castro-Oliveira ${ }^{1,2}$, M.O. Silva ${ }^{2}$, R.D.O. Carvalho, ${ }^{1,5}$, A. Anchiêta ${ }^{2}$, \\ L.J. Benevides ${ }^{1,2}$, C.J.F. Oliveira ${ }^{2}$, G. $\mathrm{Jan}^{3}$, H.C.P. Figueiredo ${ }^{4}$, \\ V.A.C. Azevedo ${ }^{1}$ and S.C. Soares ${ }^{1,2}$ \\ ${ }^{1}$ Laboratório de Genética Celular e Molecular, Instituto de Ciências \\ Biológicas, Universidade Federal de Minas Gerais, Belo Horizonte, MG, \\ Brasil \\ ${ }^{2}$ Departamento de Microbiologia, Imunologia e Parasitologia, Instituto de \\ Biologia e Ciências Naturais, Universidade Federal do Triângulo Mineiro, \\ Uberaba, MG, Brasil \\ ${ }^{3}$ INRA, STLO, Agrocampus Ouest, F-35042 Rennes, France \\ ${ }^{4}$ Departamento de Medicina Veterinária, Faculdade de Veterinária, \\ Universidade Federal de Minas Gerais, Belo Horizonte, MG, Brasil \\ ${ }^{5}$ I.M. Sechenov First Moscow State Medical University, Moscow, Russia \\ Corresponding author: S.C. Soares \\ E-mail: siomars@gmail.com \\ Genet. Mol. Res. 19 (2): gmr18599 \\ Received January 16, 2019 \\ Accepted March 31, 2020 \\ Published May 27, 2020 \\ DOI http://dx.doi.org/10.4238/gmr18599
}

\begin{abstract}
Probiotics are live nonpathogenic microorganisms extensively used in food, pharmaceutical and medicinal industries. Recently, attention has focused on specific features of probiotics and on the abilities of some long known and recently described species of this group. In general, desired features of probiotics include resistance to acid and bile salts to avoid dysbiosis and induction of immune system development. The advent of next-generation sequencing technology has propelled the genomic area, allowing a search for probiotic features in a wide range of probiotic species, especially bacteria. In this context, functional genomics analyses can help interpret big data, correlating the findings with comparative genomics analyses, in a search for direct applications. To select the articles in this review, we used the following indexing terms: (probiotics OR probiosis) AND (genomics OR transcriptomics OR
\end{abstract}


proteomics OR metabolomics OR culturomics) AND bacteria. Proteomics and transcriptomics methodologies reveal important information about proteins and transcripts differentially expressed under specific conditions that mimic host environments in health and disease. In addition, new research approaches have been developed for probiotics, such as metabiotic and metagenomic analyses of host microbiota. Also, we examined probiotic related features, including bacterial safety aspects; tolerance towards digestive constraints, such as gastric juice and bile salts; bacterial pathogen exclusion mechanisms; adhesion-related genes; antimicrobial peptides; immune development and function; omics; metagenomics; culturomics; functional genomics; transcriptomics; proteomics; metabiotics and metabolomics. In summary, currently there is considerable interest in probiotic bacteria, and structural and functional genomics analyses have potential to help research in this area.

Key words: Omics approach; Probiotics; Metabiotics; Genomics; Culturomics

\section{INTRODUCTION}

Microorganisms responsible for food fermentation and to prevent putrefaction have been used by man during centuries (Salque et al., 2013; Yang et al., 2014). It is commonly accepted that the fermentation processes adapted by man appeared due to accidental contamination and appropriate climate and environment, resulting in widely used fermented products, such as kefir, leben and koumiss (Hosono, 1992). In addition to the possibility to store fermented foods, to their enhanced nutritional value and to their safety for consumption, fermented food has had great cultural importance, highlighted by citations of some of these products in the Holy Bible and sacred books of Hinduism (Bibel, 1988; Hosono, 1992; Shortt, 1999). However, it was only after the $19^{\text {th }}$ century that the fermentation process was studied and that probiotic concepts were introduced by Louis Pasteur and Élie Metchnikoff (Johnson and Klaenhammer, 2014), the fathers of microbiology and innate immunology, respectively. Later on, Bacillus bulgaricus (currently known as Lactobacillus delbrukeckii subsp. bulgaricus) was recovered from human feces and it was shown to reduce putrefaction toxins and help in colitis treatment (Johnson and Klaenhammer, 2014).

In 1930, a Japanese microbiologist isolated a species from human feces that survived the gastrointestinal tract (GIT), identified as Lactobacillus casei, which was later used to develop the fermented milk product Yakult (Shortt, 1999). Besides the use of these probiotics in the production of fermented milk, other lactic acid bacteria (LAB) are also used in the preservation of vegetables, grains and meat (Chaillou et al., 2005). Recently, probiotics have been crossing barriers from the functional food market to pharmaceutical and therapeutic uses. This expansion is directly correlated with advances in the scientific and regulatory aspects of $\mathrm{LAB}$ related probiotics and the study of their protein delivery mechanisms (Bolotin et al., 2001; Foligné et al., 2013).

Nowadays, probiotics are widely known for their use in the treatment of functional gastrointestinal disorders (FGID) including irritable bowel syndrome, Crohn's disease and 
ulcerative colitis, in conjunction with usual medical treatments (Bibiloni et al., 2005; Sood et al., 2009; Tursi et al., 2010). This has occurred for several reasons, but mainly because there are few options of pharmaceutical treatments for FGID, and conventional treatment options have low efficacy and serious side effects (Shen and Nahas, 2009). FGID are very common and are believed to be the cause or consequence of changes in gastrointestinal microbiota (Porter et al., 2011). Consequently, probiotics have become a useful complement to the usual treatment of such diseases.

Probiotics have been found to be a favorable option not only against FGID, but also for a wide range of disorders, because they can reinforce the gut barrier function, conferring clinical benefits at distant sites through their immunomodulatory activities (Bo et al., 2014). Some studies have shown the beneficial effects of probiotics in modulating inflammatory and autoimmune diseases, such as rheumatoid arthritis (So et al., 2008), type I diabetes (Calcinaro et al., 2005), multiple sclerosis (Lavasani et al., 2010), atopic dermatitis (Viljanen et al., 2005), and myasthenia gravis (Chae et al., 2012). Moreover, experimental results strongly suggest that selected strains of probiotics can help in the treatment of cancer, neurodegenerative diseases, metabolic syndrome and psychiatric illnesses, among other pathologies. Also, there is evidence for reduction of ventilator-associated pneumonia in intensive care units patients under mechanical ventilation (Bo et al., 2014). However, one of the challenges in preclinical and clinical use of probiotics is how to select a strain with potent immune modulating properties (Chae et al., 2012).

In view of this challenge, there is a growing interest in the study of probiotic bacteria through structural and functional genomics for the discovery of probiotic-related features. Because of the development of NGS, the bacterial whole-genome sequencing has become a low cost and suitable approach for fast and accurate screening of potential probiotic candidates for treatment of each type of disorder (Didelot et al., 2012; Senan et al., 2015). This approach allows researchers to detect and discard candidate strains that have potential risk factors, such as antibiotic resistance or virulence genes. It also facilitates the analysis and description of functional mechanisms, avoiding the difficulties of isolating and growing the microorganisms (Papadimitriou et al., 2015). This new approach using NGS techniques to screen potential probiotic candidate strains makes it imperative that we understand the genomic features that should be prioritized and sought in new strains.

\section{Probiotic related features}

As a first step, the simplified definition of probiotic bacteria is originally related to live cultures that help in the maintenance of a healthy and balanced intestinal microbiota (Cronin et al., 2011). Specifically, for the GIT, probiotic features have been elucidated through the fusion of structural and functional genomics techniques. In this context, three main features of the mechanisms of probiotic action deserve attention: (i) survival through GIT passage (bile salts and gastric acidity) (Bezkorovainy, 2001), (ii) competitive exclusion and antimicrobial activity, such as microcin and hydrogen peroxide production (Konuray and Erginkaya, 2018) and (iii) modulation of the immune system of the host GIT (Johnson and Klaenhammer, 2014) (Figure 1). This includes molecular associated molecular patterns (MAMP) which may be recognized by host pattern recognition receptors (PRR) (Lebeer et al., 2010). Those mechanisms will be further described in the next sections. 


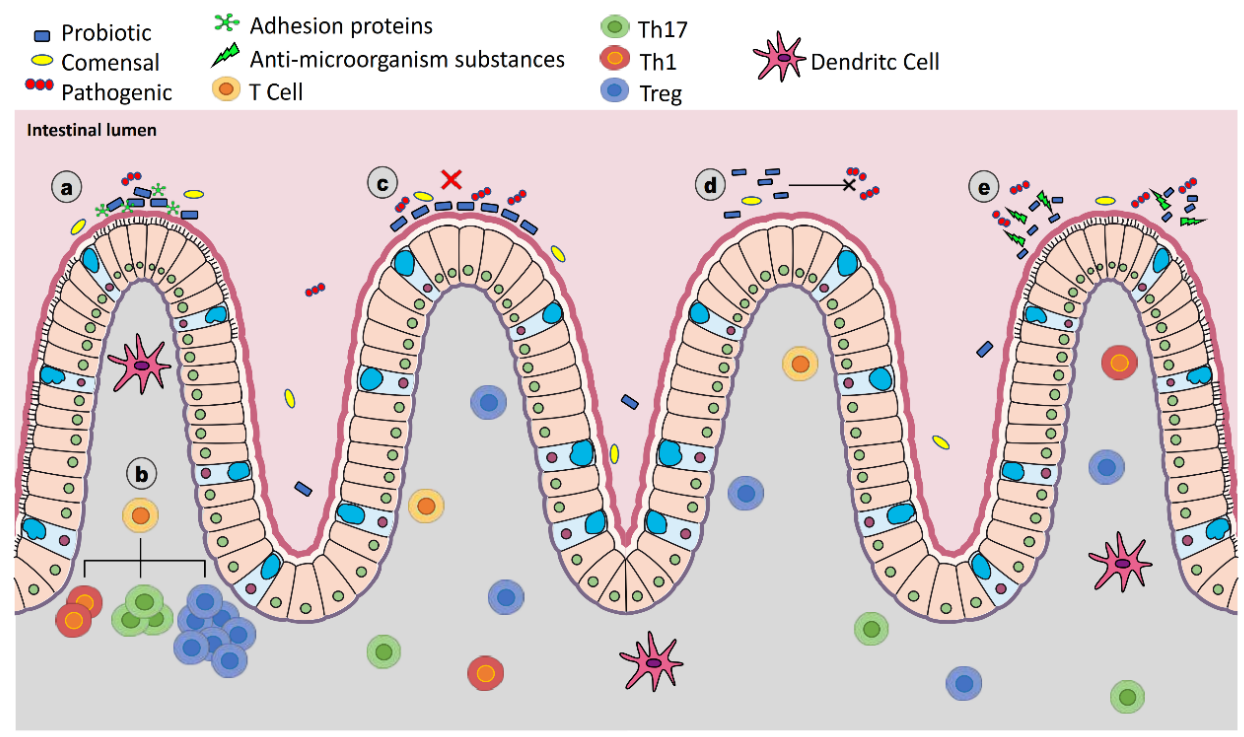

Figure 1. After surviving gastric juice and bile salts, probiotic organisms can act through specific mechanisms: (a) adhesion and colonization, (b) modulation of the immune system, (c) enhancement of the epithelial barrier, (d) competitive exclusion, (e) production of anti-microbial substances.

Various bacterial genera and species are used as probiotics, for instance: Lacticaseibacillus casei, Lactobacillus delbrueckii, Lactobacillus acidophilus, Lactiplantibacillus plantarum, Limosilactobacillus fermentum, Limosilactobacillus reuteri, Bifidobacterium breve, Bifidobacterium longum, Bifidobacterium lactis, Propionibacterium freudenreichii, Bacillus subtilis, Bacillus cereus, E. coli and Enterococcus faecium. All of these species have therapeutic applications in prevention and treatment of intestinal disorders, such as diarrhea in newborns (Ouwehand et al., 2002).

The first widely known scientific report about probiotic bacteria dates back to 1907 and demonstrated the correlation between the ingestion of LAB and the increase in longevity of Bulgarians and other populations (Howell, 1988). Fermented foods produced with the use of many bacteria of the Lactobacillus genus have been widely employed as therapeutics for the prevention or treatment of diseases due to their beneficial properties, such as relief of lactose intolerance symptoms and decrease in diarrhea due to rotavirus (Ouwehand et al., 2002).

Recently, most of studies and utilization of probiotics involve LAB, especially Lactobacillus isolated from the GIT. When it comes to the administration of probiotic bacteria, a certain amount of bacteria are necessary to exert a desired feature and consequent host response, which may vary according to the strain, use, and formulation; it is generally recommended to consume at least $10^{7}$ microorganisms per milliliter in a daily dose (Corcoran et al., 2008). 


\section{Bacterial safety aspects}

Over time, there are changes in the content and in order of genetic information of organisms due to genomic plasticity and evolutionary pressure (Soares et al., 2011). Genomic plasticity is the dynamic property of DNA that arises from genetic conversion and point mutations, rearrangements (through translocation and inversion, for example), deletions, and insertion of genetic material from other organisms (plasmids, transposons, bacteriophages, among others). These mechanisms alter the bacterial lifestyle, contributing to their adaptation to different environments and influencing their evolution (Schmidt and Hensel, 2004).

The detection and the analysis of phage regions plays a key role in the elucidation of the genomic plasticity of probiotic bacteria because they are used in fermented products for human consumption and therefore cannot harbor mobile elements that could be transferred to other bacteria. Phages are obligate parasites and most of them have a multiplication cycle that culminates in cellular lysis, through which hundreds of viral particles are released, ready to infect nearby cells (Summers, 2005). Moreover, phages are widely distributed all over the world; it is possible to find up to $10^{8}$ phages in just a drop of water from the ocean (Wommack and Colwell, 2000).

All industrial or biotechnological processes that require bacterial use for the production of fermented food products or of useful molecules could be rapidly interrupted by virulent phages. They are a primary cause of failure in the fermentative process during the industrial transformation of milk (Garneau and Moineau, 2011).

The first description of phages infecting dairy starter dates from 1935; since then, important improvements have been made, particularly in knowledge about bacterial ecology, phage genomics and resistance to environmental factors (Brüssow, 2001). There are reports of phage regions in Lactococcus species, such as Lactococcus lactis (Cavanagh et al., 2014). However, even with all the advances in the area, phage contaminations still damage fermented milk products and reduce productivity (Moineau and Lévesque, 2004). Phages may can have various origins; therefore, it is very important to study all potential sources of contamination and their consequences for the production of fermented dairy products (Garneau and Moineau, 2011).

Another way that bacteria acquire genomic material is through genomic islands (GEI). GEI may be classified as pathogenicity islands (PAI), metabolic islands (MI), symbiotic islands (SI) and resistance islands (RI). They are large genomic regions acquired through horizontal gene transfer, harboring a large number of genes (encoding similar functions and operons) with the potential to allow the bacteria to evolve in leaps (Soares et al., 2011)

Probiotic bacteria should be analyzed for PAI and RI, which contain a high concentration of virulence factors and antibiotic resistance genes, respectively, and could be transferred to other organisms, compromising the safety aspects of the bacteria. Probiotic bacteria should only contain natural resistance, with no trace of virulence factors or antibiotic resistance genes in unstable regions, such as GEI, phages, and plasmids (Salminen et al., 1998).

There are some specific aspects that characterize probiotic action within the host GIT that will be discussed in the next section. Genomic islands related to interaction with the host and to persistence within its digestive tract have also been described by 
comparative genomics (Kankainen et al., 2009). Their instability over time and in cultures evidenced the need for quality assurance and control measures targeting genome stability in probiotics (Sybesma et al., 2013).

\section{Tolerance towards digestive constraints, gastric juice and bile salts}

One of the most important attributes of a probiotic microorganism is its ability to survive the GIT environment. A study with comparative genomics analyzed the niche-based stress-responsive genes of two Lactobacillus helveticus strains: MTCC 5463 (a potential probiotic) and DPC4571 (a cheese starter); 5463 apparently has many genes involved in stress response. This potential probiotic strain has a larger number of genes related to heat, osmotic, cold and oxidative stress resistance than DPC 4571 (Senan et al., 2014).

Functional genomics studies have been complementing and elucidating some questions related to stress response. Using transcriptomics and proteomics, a study of the probiotic Lacticaseibacillus rhamnosus GG analyzed the effects of bile stress and demonstrated that 316 transcripts changed in expression level and 42 proteins (intracellular and surface-exposed), were differentially abundant. The the changes were associated with the adaptation process of this bacterium (Koskenniemi et al., 2011). Performing the same omics study on Bifidobacterium longum BBMN68, the expression level of 236 transcripts changed significantly and 44 proteins were differently abundant. A hypothesis involving the modification of cell membrane composition (cyclopropane fatty acid increases and transmembrane proteins decreases) was confirmed with a surface hydrophobicity assay (An et al., 2014).

\section{Bacterial pathogens exclusion mechanisms}

Competitive exclusion of pathogens is another criterion in the selection of probiotic bacteria. Among the mechanisms of action, there are, for instance, enhancement of the epithelial barrier, production of anti-microbial substances, competitive exclusion of bacterial pathogens, increased adhesion to intestinal mucosa and modulation of the immune system (Bermudez-Brito et al., 2012). Associated features may include surface compounds involved in aggregation, coaggregation, and adhesion, as well as specific biosynthesis pathways.

\section{Adhesion-related genes}

In addition to survival through the GIT, adhesion to the intestinal epithelium is another factor that may contribute to probiotic activity, through exclusion mechanisms. The interaction between microbe and host occurs via adhesion-related proteins that recognize and bind to specific receptor regions of the host cell, activating the innate response, promoting invasion or bacterial colonization. Adhesion may be mediated by pili or fimbriae extending out from the bacterial cell wall or Microbial Surface Components Recognizing Adhesive Matrix Molecules (MSCRAMMs) (Soto and Hultgren, 1999).

Preliminary in vitro studies using intestinal epithelial cells revealed multiple probiotic Lactobacillus producing adhesins (Chauviere et al., 1992; Tuomola and Salminen, 1998) and Bifidobacterium spp. was shown to adhere to the human intestinal mucus (He et 
al., 2001). Access to the genomic sequence data combined with genomic techniques helped to elucidate the adhesion mediators. Most of these are secreted or bound to the cell wall in a sortase-dependent way, aiming to interact with the intestinal epithelium (Vélez et al., 2007; Lebeer et al., 2008). Studying 43 Lactobacillus strains, Harris et al. (2017) used Cluster of Orthologous Groups (COG) to identify at least one sortase A gene for each. Seven genomes among them have an extra sortase $\mathrm{A}$, of which, five have a sortase $\mathrm{C}$ gene and a putative pilus operon.

In L. acidophilus NCFM, an in silico search on the genome allowed the identification of five cell surface adhesion proteins, including: one fibronectin binding protein $(\mathrm{FbpA})$, one S-layer protein $(\mathrm{SlpA})$, one mucin binding protein $(\mathrm{Mub})$ and two homologous R28 proteins involved in Streptococcus adhesion (Buck et al., 2005).

Through mutational analyses, FbpA, SlpA, and Mub were shown to contribute to adhesion to Caco-2 epithelial cells. Similarly, one stress response protein and one aggregation promoting factor (both surface proteins) were later found in other studies, which are also contribute to adherence to Caco-2 cells (Goh and Klaenhammer, 2010; O'Flaherty and Klaenhammer, 2010).

Slp genes may indeed be involved in adhesion to host cells in various probiotics such as lactobacilli (do Carmo et al., 2018) and propionibacteria (do Carmo et al., 2017). Inactivation of the corresponding Slp gene accordingly suppresses interaction with host cells in L. acidophilus (Konstantinov et al., 2008) and in P. freudenreichii (do Carmo et al., 2017).

Comparative genomics was used with two L. rhamnosus strains and revealed the presence of genomic islands; one of them, predicted in L. rhamnosus GG, harbors genes coding for three secreted proteins, sortase-dependent pili, encoded by a $\operatorname{spaCBA}$ operon that were later confirmed through experimental analyses as pili encoding genes (Kankainen et al., 2009). Functional annotation was used to characterize the probiotic potential of Bacillus coagulans HS243, in which 11 genes were predicted as adhesion-related proteins, among them: enolase, fibronectin binding protein and flagellar hook associated proteins (Kapse et al., 2018).

The adhesion mechanism is an important property to select a probiotic strain and using in silico analyses it is possible to determine more details of the adhesion sites, such as mucin and binding to fibronectin (Papadimitriou et al., 2015)

\section{Antimicrobial peptides}

The $\mathrm{LAB}$ action in the conservation of food is due to both medium acidification $(\mathrm{pH}$ 3.5 to 4.5 ) and the production of numerous bacterial agents, such as organic compounds and bacteriocins (Van de Guchte et al., 2001). Bacteriocins are bacterial produced peptides, which act against other microorganisms and to which the producer has specific immunity mechanisms (Cotter et al., 2005).

The first work reporting the mechanism of action of bacteriocin mediated inhibition reported the discovery of antagonists among Escherichia coli strains (Gratia, 1925). Although the use of bacteriocins was formally proposed later (Hirsch et al., 1951), it is probable that humans were already benefitting from bacteriocin production for $\sim 8,000$ years since the first production of cheese and fermented food (Cotter et al., 2005). 
Bacteriocins were first classified in 1993 (Klaenhammer, 1993); since then, modifications of this classification have been proposed (Cotter et al., 2005). Bacteriocins are divided into classes I, II, III and IV. Class I harbors lantibiotics or thermostable peptides with a molecular weight below $5 \mathrm{kDa}$ produced by gram-positive bacteria and which present atypical amino acids, such as lanthionine (Lan), methyl lanthionine (MeLan) and others (Karpiński and Szkaradkiewicz, 2013). The class II bacteriocins are represented by non-lanthionine bacteriocins; they are thermostable and have $10 \mathrm{kDa}$ molecular weight, slightly heavier than class I. Due to differences in the structure of class II bacteriocins, they are divided into subclasses: pediocin (IIa), lactacin F (IIb), enterocin (IIc) and lactococcin A (IId) (Cotter et al., 2005; Karpiński and Szkaradkiewicz, 2013). Using comparative genomics to characterize the potential probiotic feature of L. plantarum ZJ316, a study showed that this strain is an important producer of bacteriocins, since it is capable of producing at least two classes of bacteriocins, IIb and IIc (Li et al., 2016).

Bacteriocins weighting more than $30 \mathrm{kDa}$ are classified in class III. They are thermolabile and are mainly produced by gram-positive bacteria (van Belkum and Stiles, 2000). Class III bacteriocins are also divided into subclasses, where a group is represented by bacteriolytic enzymes (bacterial lysins), which lyses sensitive strains, and the non-lytic group of antimicrobial proteins, represented by lysostaphin and enterolysin A (Cotter et al., 2005; Karpiński and Szkaradkiewicz, 2013). Using comparative genomics, a potential probiotic strain of Lactococcus lactis was analyzed for bacteriocins. Based on an annotated and curated genome, strain NCDO 2118 presented one bacteriocin for each of three classes, of which two were not previously predicted in the genome sequence (classes I and III) (Oliveira et al., 2017).

Class IV includes bacteriocins that require carbohydrates or lipids in their molecule to have a complete activity (Jack et al., 1995). Compared to the use of antibiotics in infection treatments, bacteriocins are more target-specific, have low or no toxicity to eukaryotic cells, and are active against antibiotic-resistant strains. However, there is still a lack of evaluation about their effect on the gut microbiota and also their role in probiotic effects in healthy animals (Umu et al., 2016).

Besides the gut, the skin and other mucosal tissues are in direct contact with external aggressive agents and consequently are continuously exposed to huge numbers of pathogenic microorganisms. To combat these pathogens, the epithelial/mucosal surface and the microbiota induce various mechanisms that directly kill or inhibit the growth of the pathogens ( Gallo and Hooper, 2012; Dickson et al., 2013; Bao et al., 2017). The bacteria of the microbiota also produce bacteriocins and these molecules are also essential for host protection in health and disease.

\section{Immune development and function}

Coevolution between microbes and mammals, including humans, has brought many mutual benefits, which are affected by the diversity and niches of these microbes, especially the gut bacteria, which aid in the prevention of many human diseases. One of the various benefits of this coevolution for humans is that the microbiota assist in the development of the human immune system (Francino, 2014). One of the clearest types ofevidence of this role is that germ-free animals, are severely affected deficiencies in the development of the immune system in the gut (Kabat et al., 2014). Animals depleted of gut 
microbiota have smaller Peyer's patches, fewer antimicrobial peptides, antibodies and B cells, as well as other immunodeficiencies (Round and Mazmanian, 2009). Also, immune system development induced by the gut microbiota is associated with host protection against inflammatory disorders (Belkaid and Hand, 2014) and infectious diseases (Duan et al., 2010).

Besides their role in the effective development of the immune system, probiotics present potent immunomodulatory and anti-inflammatory activities (as shown in Figure 1), acting in the prevention and treatment of inflammatory and autoimmune diseases. Because of these properties, various dairy products are popular and widely consumed, especially fermented milk (de Moreno de LeBlanc et al., 2011).

An important strategy of mammals to maintain the homeostasis of the intestinal environment is to minimize contact between gut lumen microorganisms and the surfaces of intestinal epithelial cells (IEC) (Llewellyn and Foey, 2017). Various types of pattern recognition receptors are expressed by intestinal immune cells, including Toll-like receptors (TLR), NOD-like (nucleotide oligomerization domain) receptors and G protein-coupled receptors (GPCR), which recognize microbial compounds (PAMPS, pathogen-associated molecular patterns); but this recognition or activation is limited (Hill and Artis, 2010; Llewellyn and Foey, 2017). On the other hand, concerning microbiota and immunity, these live microorganisms are able to increase or modulate the activity of gut dendritic cells, monocytes, macrophages, natural killer cells and $\mathrm{T}$ cells, controlling the production/activity of chemokines, cytokines and antibodies ( Klaenhammer et al., 2012; Frei et al., 2015; La Fata et al., 2018).

Evaluating the probiotic potential of Lactobacillus jensenii TL2937 in pigs via the extracellular proteome, six proteins with potential immunogenic properties were found, incluiding chaperonic protease $\mathrm{ClpB}$, Rpf protein (possesses a G5 protein family domain present in various extracellular peptidases, responsible for cleaving human IgA) (Bateman et al., 2005; Gilad et al., 2011).

In L. acidophilus, the surface layer protein SlpA was shown to mediate the key immunomodulatory effect of this probiotic by interacting with DC-SIGN receptors at the surface of dendritic cells (Konstantinov et al., 2008). Propionibacteria, recently identified as human commensals with a key immunomodulatory role, mitigate intestinal inflammation. Accordingly, their presence in infant gut microbiota correlates with reduced incidence of necrotizing enterocolitis (Colliou et al., 2017). In P. freudenreichii, these immunomodulatory properties were evidenced in vitro and in vivo (Foligné et al., 2010). They rely on specific surface proteins (Le Maréchal et al., 2015), are highly straindependent (Foligné et al., 2013) and require a set of Slps (Deutsch et al., 2017).

Based on these considerations and other published data, especially in the last five years, we may state that the microbiota is involved in the immune response to virtually all diseases already studied, whether they are of infectious origin or not. That is, dysbiosis of microbiota, whether in the intestine and/or in other tissues, is closely related to prevention and/or treatment of infections, inflammatory diseases, autoimmune diseases, cancers, neurodegenerative diseases, depression, anxiety, diet, trauma, metabolic syndrome and related diseases among other disorders (Kang and Im, 2015; Sander, 2017; Westfall et al., 2017; Lee et al., 2018). 


\section{OMICS APPLIED TO PROBIOTIC BACTERIA}

\section{Genomics}

The first completely sequenced genome of the LAB group was L. lactis subsp. lactis IL1403 strain, published in 2001. This study revealed biosynthetic pathways, phages and some of the components that participate in aerobic metabolism (Bolotin et al., 2001).

In 2002, a program intended for the mass sequencing of LAB genomes was announced by Lactic Acid Bacteria Genome Sequencing Consortium (Klaenhammer et al., 2002). Currently, more than 100 Lactococcus genomes are available on the NCBI database (National Center for Biotechnology Information http://www.ncbi.nlm.nih.gov/genome/genomes/156), of which 39 are complete genomes.

LAB have small genomes, approximately $2 \mathrm{Mb}$ in length on average, coding for approximately 2000 genes, but range from 1600 to 3000 genes, according to the species. This variation results from $\mathrm{LAB}$ evolution through gene loss, duplication, and acquisition (Khalid, 2011).

Bolotin et al. (2004) showed that dairy streptococci have undergone reductive evolution, resulting in divergence between them and pathogenic species of streptococci. The most remarkable example is Streptococcus thermophilus, which diverged from other species of Streptococcus through the loss of virulence factors, such as those involved in adhesion and antibiotic resistance.

Many studies highlight the importance of genomic sequencing in the discovery of new features related to the $\mathrm{LAB}$, such as the identification of genes encoding proteolytic enzymes (which participate in cheese maturation) in L. helveticus (Smeianov et al., 2007). The sequencing of the first Lactobacillus species: L. plantarum WCFS1 (Kleerebezem et al., 2003), Lactobacillus johnsonii NC533 (David et al., 2004; Denou et al., 2008) and $L$. acidophilus NCFM (Altermann et al., 2005), revealed some interesting characteristics, such as lifestyle adaptation islands, lack of biosynthesis pathways, and unique structures named potential autonomic units (PAU).

Bioinformatics approaches have helped identify the citrate catabolic pathway in $L$. casei (Díaz-Muñiz et al., 2006), and other studies have identified genes responsible for decarboxylation of a branched-chain alpha-ketoacid of L. lactis (De La Plaza et al., 2004; Smit et al., 2005). Genomic sequencing has also played a role in the elucidation of LAB probiotic effects; for instance in the study of antimicrobial compounds and immunomodulatory mechanisms of Lactobacillus reuteri (Saulnier et al., 2011), comparative analysis of pilus-associated genes and metabolic pathways in Lactobacillus rhamnosus and Lactobacillus casei (Douillard et al., 2013), and identification of adhesionassociated proteins (cwaA) in L. plantarum (Zhang et al., 2015).

Assessment of the probiotic properties of a selected microorganism requires many experiments in vitro and in vivo. This takes considerable time. The omics approach allows one to speed up these studies by enabling the identification of potential probiotic microbes. Recently, Salvetti et al. (2018) studied 269 species of Lactobacillaceae and Leuconostocaceae with a phylogenetic approach. Twenty-nine ribosomal proteins and housekeeping genes were compared. They conclude that the Lactobacillus genus has various subclades, which may lead to reclassification of the lactobacilli. This grouping facilitates development of accurate molecular markers to help avoid problems sucha as the 
the misidentification of probiotic strains. More recently, 2459 high-quality whole genomes were analyzed and, based on a polyphasic phylogenetic approach, reclassification of the Lacatobacillus genus into 25 genera and fusion of the Leuconostocaceae and Lactobacillaceae families was proposed (Zheng et al., 2020).

Besides the genomic approach (Figure 2), other omics have been providing information to help understand the divergence and evolution many species over time (Pfeiler and Klaenhammer, 2007). Using an omics approach, it is possible, for example, to correlate protein data with survival within the host under stress conditions or secreted proteins that may exert a specific role in probiotic effects of certain strains, through analysis of bacterial-host interactions.

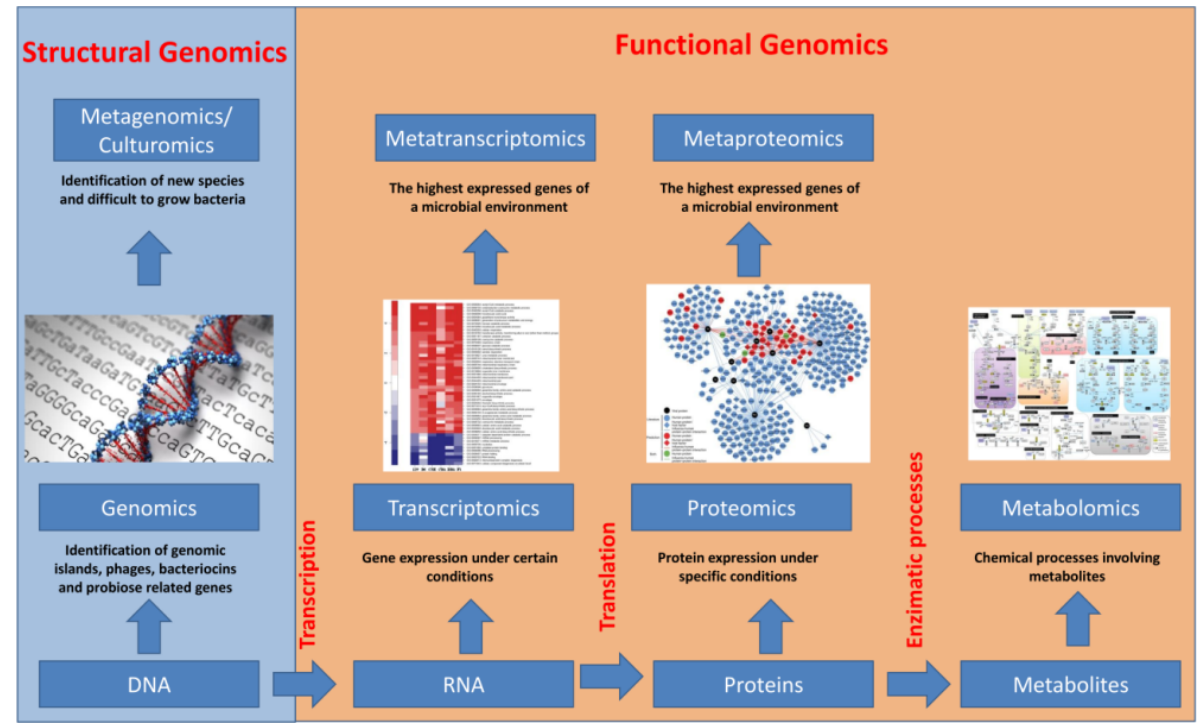

Figure 2. The goals of omics approaches.

\section{Metagenomics}

Through metagenomic (Figure 2) analyses, it is possible to access physiological and genetic information about uncultured organisms, such as the human GIT microbiota, through the sequencing of $16 \mathrm{~S}$ rRNA genes and by shotgun sequencing (Handelsman, 2005). This type of tool gives important genetic information for uncultured organisms, helping develop novel hypotheses of microbial function. Before metagenomics, the methodology consisted of cloning DNA from environmental sources, followed by functional expression screening (Handelsmanl et al., 1998; Handelsman, 2005), which is time consuming and limits the number of strains and species that can be studied.

A pioneer study in this area consisted in the large-scale metagenomics projects in in the Sargasso sea, in which a massive microbial population was characterized through 1,045 billion base pairs from seawater samples. This large number of sequences provided important information on the diversity, gene content and the relative abundance of the organisms (Venter, 2004). 
The development of metagenomics, mainly with the advent of next-generation sequencing technologies (NGS), and the creation of the International Human Microbiome have both boosted the field and opened a new door in analyses of bacteria/host interactions. The culture-free methodology used by NGS technologies expanded the analyses of microbial composition and may now be used not only to predict new probiotics from a comparison of the microbiota from healthy and diseased individuals, but may also be used to analyze the composition of the microbiota before and after administration of a given probiotic bacterium (McFarland, 2014).

In a study of the microbiota of genetically obese mice and their lean littermates, Turnbaugh et al. (2006) demonstrated through metagenomics analyses that the obesity was associated with an abundance of two groups of bacteria: Bacteriodetes and Firmicutes.

Nobutani et al. (2017) administrated Lactobacillus gasseri strain CP2305 or a placebo to patients with irritable bowel syndrome. They identified 87 genera, among which 13 differed in frequency; the genera Dorea, Enterococcus, and Dialister decreased in the CP2305 group.

\section{Culturomics}

Some studies have demonstrated the usefulness of a culturomics approach (Figure 2) for probiotic analyses (Dubourg et al., 2014). A culturomics approach consists in growing under multiple culture conditions, followed by matrix-assisted laser desorption/ionization-time of flight mass spectrometry and 16 rRNA analysis for the identification of less representative species in the sample (Lagier et al., 2016, 2018). This technique has helped identify new organisms that are generally not found through metagenomics techniques (Pfleiderer et al., 2013; Dubourg et al., 2014).

As an aid to identify a larger number of organisms, culturomics can identify populations with a concentration of less than $10^{3} \mathrm{CFU}$ per $\mathrm{mL}$, which is below what can be detected in large-scale metagenomics studies (Lagier et al., 2012). Culturomics was reborn with studies of environmental microbiologists. For instance, Bollman et al. (2007) created a new method that was able to isolate almost numerous microorganims present in a specific aquatic environmentthat were not detected with other methods.

The first study of the microbial composition of the gut microbiota using culturomics dates from 2012. Lagier et al. (2012) grew microorganisms under 212 different culture conditions and used mass spectrometry and 16S rRNA amplification and sequencing to help identify the colonies found. the culturomics analyses of the microbiome resulted in 31 new species in addition to more than 100 species never described from the human gut before.

Culturomics and metagenomics leverage the potential of identification of new species. They complement each other, providing greater knowledge and understanding of new and/or difficult-to-grow bacteria. A database was created in order to group several prokaryotic species associated with human beings (commensals or pathogens), highlighting the importance of culturomics and metagenomics. The 2172 species listed were classified into 12 different phyla, most of them being Proteobacteria, Firmicutes, Actinobacteria and Bacteroidetes (Hugon et al., 2015). More recently, it was reported that the number of species had increased, totalng 2776 species, due to culturomics techniques that facilitated the identification of new bacterial species (Bilen et al., 2018). 
Stool samples of malnourished and healthy patients from Senegal and Niger were analyzed using culturomics and metagenomics. Besides finding a decrease in the diversity of fecal microorganisms and an enrichment of potentially pathogenic bacteria, they identified some probiotic bacteria only in healthy children. Also, new species were identified, including Propionibacteriaceae and Bacillaceae species (Tidjani Alou et al., 2017).

\section{Functional genomics}

\section{Transcriptomics}

The area of transcriptomics (Figure 2) may elucidate how genes are involved in adaptation for specific conditions. Van der Meulen et al. (2016) identified 375 novel regulatory mRNAs in L. lactis MG1363 involved in stress response and metabolic processes, such as internal promoters, operon structures and novel ORFs. Using probiotic preparations containing L. acidophilus, L. casei and L. rhamnosus, an in vivo experiment was performed with volunteers to analyze the gene-regulatory networks and pathways in the human mucosa. A significant variation was observed among the transcriptomics results of the volunteers; however, various factors, such as the resident microbiota, diet, genetic background and lifestyle can affect a probiotic response, (van Baarlen et al., 2011).

Functional genomics may also contribute to refine phylogenetic studies due to the high homology among some bacteria, such as L. acidophilus. Using core and transcriptomic data it was possible to identify small ORFs that are highly conserved and transcribed in various species of this group, highlighting new possibilities to characterize and present new probiotics to the market (Crawley and Barrangou, 2018). Studying the transcription profile of genes associated with adhesion and stress response of the probiotic L. acidophilus NCFM, Weiss and Jespersen (2010) used specific conditions to mimic the GI tract in vitro. During gastric digestion, the genes encoding GroEL, ClpP and DnaK showed considerable up-regulation. The genes encoding mucin-binding and fibronectin-binding proteins were upregulated in the incubation process (duodenal juice and bile).

A major breakthrough in this field was in vivo transcriptomics. Introduction of a pure culture of a probiotic bacterium, constrained in a dialysis bag, within the colon of a rabbit, allows monitoring upregulation of genes related to digestive constraint adaptation. First described in an in vivo proteomic study of Bifidobacterium longum in rabbits (Yuan et al., 2008), it was then adapted to an in vivo transcriptomic study of $P$. freudenreichii in the colon of pigs (Saraoui et al., 2013). This study revealed over expression of key genes involved in specific carbohydrate catabolisms, in alternative pathways to produce NADH, NADPH, ATP and precursors (utilizing of propanediol, gluconate, lactate, purine and pyrimidine and amino-acids), as well as genes specifically expressed during cell division.

\section{Proteomics}

Proteomics (Figure 2) allow the study of the expression of a large range of proteins from a specific organism. A proteomic analysis comparing a wild strain of L. plantarum with a mutant one under physiological and heat stress conditions showed an induction of proteins related to re-folding of proteins subject to cellular damage, elucidating the 
importance of CtsR regulon control in lactic acid bacteria (Russo et al., 2012). Another study using proteomics comparison of three L. plantarum strains confirmed the bile resistance characteristics of $L$. plantarum $299 \mathrm{~V}$, already known as a probiotic. The analyses were made using strains with different levels of bile resistance and helped to understand how these strains modulate their metabolism to survive in stress environments (Hamon et al., 2011).

In a study of a long-chain carbohydrate known to be a prebiotic, called inulin, it was observed that L. plantarum was able to use this compound and an operon (fosRABCDXE) for inulin metabolism was identified in this genome (Buntin et al., 2017).

Proteomic analyses of Bifidobacterium longum, isolated from stool, was performed to evaluate protein expression under the effect of bile salts. Using different degrees of exposure to bile, it was possible to identify 34 different proteins differentially regulated, amongst them: general stress response chaperones and some enzymes of pyruvate and glycolysis catabolism (Sánchez et al., 2005). B. longum was also used in an in vivo proteomic study. Incubation of this probiotic bacterium within the colon of rabbits led to the induction of a set of specific proteins (Yuan et al., 2008). This set included proteins related to the metabolism, to translation, and to intestinal adaptation, such as EF-Tu which is a Bifidobacterium adhesin-like factor, and bile salt hydrolase (BSH).

Concerning probiotic propionibacteria, proteomics was used to reveal mechanisms induced in acid (Jan et al., 2001), bile salts (Leverrier et al., 2003) and thermal adaptation (Leverrier et al., 2004). Some of these key stress proteins were also induced in a Swiss-type cheese matrix (Gagnaire et al., 2015), in accordance with the protective role of this food matrix towards digestive constraints

\section{Metabiotics and metabolomics}

Another omic strategy recently applied to probiotics analysis is metabolomics (Figure 2). Through this approach it is possible to determine and quantify the metabolites present intracellularly (Mozzi et al., 2013). Some metabolites promote health, and are named Metabiotics. They are metabolites from the structural components, metabolites or signaling molecules of probiotic bacteria, such as lactic acid, short chain fatty acids (SCFAs), linoleic acid, some glycoproteins/peptides and potentially carcinogenic metabolites. Metabiotics have beneficial bioactive substances that act in host-specific physiological functions, regulatory, metabolic and/or behavior reactions (Shenderov, 2013; Sharma and Shukla, 2016). Among these, SCFAs are the most studied, being a source of energy for colonocytes and the modulators of various metabolic activities (Shenderov, 2013).

Metabiotics-producing bacteria include not only the well-known probiotic species of Lactobacillus, Escherichia, and Enterococcus, but also other species in the dominant human intestinal phyla (Bacteroides, Firmicutes, Proteobacteria, Actinobacteria, and Archae) for nutrition and medical purposes (Shenderov, 2013).

Probiotics produce several bioactive substances with beneficial effects in combatting GIT diseases, which help in homeostasis and competitive exclusion of pathogens (Verma and Shukla, 2013). More interestingly, the multifunctional SCFA acetate plays an important role in epithelial cell division, ileal motility and other functions (Hong et al., 2005). Moreover, an increase in the colic content of propionate, another SCFA, as a 
result of probiotic propionibacteria consumption, was correlated with enhanced apoptotic depletion of colon cancer cells in human microbiota inoculated rats (Lan et al., 2008). At the cell level, it was shown to induce apoptosis by acting on cancer cell mitochondria, triggering the intrinsic cell death pathway, leading to caspase activation (Jan et al., 2002) and increased susceptibility to induced cell death (Cousin et al., 2016).

The most widely studied metabiotic is SCFA butyrate, produced by Faecalibacterium prausnitzii and Eubacterium rectale in the gut (Zhong et al., 2014), which has the potential to differentiate between cancer and normal cells to exert epigenetic effects and inhibit the growth of cancer cells. Butyrate has been associated with the induction of apoptosis in colon cancer cells due to its ability to convert procaspase 3 to active caspase 3 (Medina et al., 1997).

Among beneficial metabolites produced by probiotic bacteria, recent studies have drawn attention to gamma-aminobutyric acid (GABA) in the context of the gut-brain axis and of altered brain function ( Janik et al., 2016; Dinan and Cryan, 2017), and to trimethylamine/trimethylamine N-oxide (TMA/TMAO) in the context of cardiovascular disease (Bu and Wang, 2018).

Some technologies are extremely useful for metabolomics studies; the most current and integrated methods related to separation and detection processes are liquid chromatography (LC: high-performance, HPCL and ultra performance, UPLC) and mass spectrometry (MS). HPLC technique is able to separate multiple compounds according to stationary phase and UPLC gives results similar to HPLC; however, this technology has greater capacity, resolution, sensitivity and higher speed (Mozzi et al., 2013). Major progress has furthermore been achieved by the use of nuclear magnetic resonance spectroscopy (Dunn and Ellis, 2005; Sugahara et al., 2015; Janik et al., 2016).

\section{Integrative omics and enrichment approaches}

Identification of a single specific factor associated with a probiotic effect might have limited value for selecting bacterial strains and therapeutic rationales. In this case, a multi-omics approach compared to a single-omic analysis may offer greater advantages, as they cover a broader range of information through the identification of associated factors from different biological processes, such as gene expression, protein synthesis, posttranslational modifications and cellular metabolic processes (Perakakis et al., 2018). The integration of data from genomic, transcriptomic and metabolomic analysis can be a powerful tool to investigate and rapidly validate new molecular probiotic features. In this context, promising achievements have been made by studies investigating molecular resistance features towards stressful conditions that bacterial probiotic strains face during the manufacturing process. For example, Bianchi et al. (2020) identified altered amino acid production, as well as metabolic and health-promoting changes in probiotic strains of $L$. paracasei, Streptococcus thermophilus, and bifidobacteria as a result of different conditions of manufacture and formulation through an integrative approach of functional proteomics, metabolomics, and in vivo analyses.

Although promising, integrative omics currently presents great challenges such as a need to development and employ bioinformatics pipelines and algorithms to associate and harmonize large amounts of data generated by the different high-throughput platforms (Jiménez-Pranteda et al., 2015). Recently, feature-annotation enrichment analysis has been 
extensively used to identify biological processes by comparing de novo data with accumulated biological data deposited in public databases. This approach offers a rapid solution to systematically classify large feature lists into pathways, cellular localization and function categories (Gandhi and Shah, 2017). A plethora of enrichment tools have emerged in the last 20 years, and are being improved to become more suitable as data-mining exploration tools (Huang et al., 2009).

\section{CONCLUSIONS}

Probiotic bacteria have been used by humans for a long time in the maturation of cheese and the production of fermented food. However, their importance has been only recently highlighted with the study of their safety aspects, exclusion mechanisms, survival through the host GIT and production of immunomodulatory and anti-inflammatory proteins. With the advent of NGS technologies for structural and functional genomics, coupled with whole proteomics analyses using mass spectrometry, there are several new possibilities for probiotic identification using metagenomics of GIT microbiota to investigate microbial changes under disease conditions and after probiotic administration. We can highlight the importance of auxiliary techniques, such as culturomics for the identification of bacteria not detected in metagenomics, for example. In addition, both approaches may be used to elucidate problems with identification of probiotic strains.

Omics will allow seeking for probiotic features in new and promising strains of probiotics. Based on the set of data acquired from established probiotic strains, omics will allow screening strains for expression of key molecules involved in beneficial interactions with the host. These include MAMPs such as Slps and pili, key metabolites such as GABA, as well as proteins involved in adaptation to the host gut.

Genomic studies may also be used in the analyses of genome plasticity of probiotic and non-probiotic related strains, for the identification of genes related to each of the probiotic features. Finally, transcriptomics and proteomics may help in the identification of differentially expressed genes in probiotic and non-probiotic species for the later elucidation of metabolic pathways and protein-protein interactions analyses. Future improvements in the area may involve the identification of probiotic-pathogenic and bacterial-host proteinprotein interactions from a wider systems biology perspective. The omics approach brought new paths and means to analyze characteristics of future potential probiotic bacteria and broaden our understanding of the different ways theh interact with the gut microbiota of the host; this was only possible with an integrative omics approach.

\section{ACKNOWLEDGMENTS}

The authors thank the Brazilian Federal Agency for the Support and Evaluation of Graduate Education (CAPES), the Minas Gerais Research Foundation (FAPEMIG) and the National Council for Scientific and Technological Development $(\mathrm{CNPq})$ for their support.

\section{AUTHOR CONTRIBUTIONS}

Images creation: LCO, MO, SCS; Writing - original draft: LCO, HCPF, VACA, SCS; Writing - review \& editing: LCO, MO, AS, LJB, CJFO, GJ, RDOC, HCPF, VACA, SCS; Supervision: CJFO, HCPF, VACA, SCS 
Probiotic bacteria - omics approach

\title{
CONFLICTS OF INTEREST
}

\author{
The authors declare no conflict of interest.
}

\section{REFERENCES}

Altermann E, Russell WM, Azcarate-Peril MA, Barrangou R, et al. (2005). Complete genome sequence of the probiotic lactic acid bacterium Lactobacillus acidophilus NCFM. Proc. Natl. Acad. Sci. 102: 3906-3912. doi:10.1073/pnas.0409188102.

An H, Douillard FP, Wang G, Zhai Z, et al. (2014). Integrated Transcriptomic and Proteomic Analysis of the Bile Stress Response in a Centenarian-originated Probiotic Bifidobacterium longum BBMN68. Mol. Cell. Proteomics. 13: 2558-2572. doi:10.1074/mcp.M114.039156.

Bao Y, Al KF, Chanyi RM, Whiteside S, et al. (2017). Questions and challenges associated with studying the microbiome of the urinary tract. Ann. Transl. Med. 5: 33-33. doi:10.21037/atm.2016.12.14.

Bateman A, Holden MTG and Yeats C (2005). The G5 domain: a potential N-acetylglucosamine recognition domain involved in biofilm formation. Bioinformatics. 21: 1301-1303. doi:10.1093/bioinformatics/bti206.

Belkaid Y and Han TW (2014). Role of the Microbiota in Immunity and Inflammation. Cell. 157: 121-141. doi:10.1016/j.cell.2014.03.011.

Bermudez-Brito M, Plaza-Díaz J, Muñoz-Quezada S, Gómez-Llorente C, et al. (2012). Probiotic Mechanisms of Action. Ann. Nutr. Metab. 61: 160-174. doi:10.1159/000342079.

Bezkorovainy A (2001). Probiotics: determinants of survival and growth in the gut. Am. J. Clin. Nutr. 73: 399-405.

Bianchi L, Laghi L, Correani V, Schifano E, et al. (2020). A Combined Proteomics, Metabolomics and In Vivo Analysis Approach for the Characterization of Probiotics in Large-Scale Production. Biomolecules. 10: 157. doi: 10.3390/biom10010157.

Bibel DJ (1988). Elie Metchnikoff's Bacillus of Long Life. ASM News. 54: 661-665.

Bibiloni R, Fedorak RN, Tannock GW, Madsen KL, et al. (2005). VSL\#3 Probiotic-Mixture Induces Remission in Patients with Active Ulcerative Colitis. Am. J. Gastroenterol. 100: 1539-1546. doi:10.1111/j.15720241.2005.41794.x.

Bilen M, Dufour J-C, Lagier JC, Cadoret F, et al. (2018). The contribution of culturomics to the repertoire of isolated human bacterial and archaeal species. Microbiome. 6: 94. doi:10.1186/s40168-018-0485-5.

Bo L, Li J, Tao T, Bai Y, et al. (2014). Probiotics for preventing ventilator-associated pneumonia. Cochrane Database Syst. Rev. doi:10.1002/14651858.CD009066.pub2.

Bollmann A, Lewis K and Epstein SS (2007). Incubation of Environmental Samples in a Diffusion Chamber Increases the Diversity of Recovered Isolates. Appl. Environ. Microbiol. 73: 6386-6390. doi:10.1128/AEM.01309-07.

Bolotin A, Quinquis B, Renault P, Sorokin A, et al. (2004). Complete sequence and comparative genome analysis of the dairy bacterium Streptococcus thermophilus. Nat. Biotechnol. 22: 1554-1558. doi:10.1038/nbt1034.

Bolotin A, Wincker P, Mauger S, Jaillon O, et al. (2001). The Complete Genome Sequence of the Lactic Acid Bacterium. Genome Res. 731-753. doi:10.1101/gr.169701.

Brüssow H (2001). Phages of dairy bacteria. Annu. Rev. Microbiol. 55: 283-303.

$\mathrm{Bu} \mathrm{J}$ and Wang Z (2018). Cross-Talk between Gut Microbiota and Heart via the Routes of Metabolite and Immunity. Gastroenterol. Res. Pract. 2018: 1-8. doi:10.1155/2018/6458094.

Buck BL, Altermann E, Svingerud T and Klaenhammer TR (2005). Functional Analysis of Putative Adhesion Factors in Lactobacillus acidophilus NCFM. Appl. Environ. Microbiol. 71: 8344-8351. doi:10.1128/AEM.71.12.83448351.2005

Buntin N, Hongpattarakere T, Ritari J, Douillard FP, et al. (2017). An inducible operon is involved in inulin utilization in Lactobacillus plantarum strains, as revealed by comparative proteogenomics and metabolic profiling. Appl. Environ. Microbiol. doi:10.1128/AEM.02402-16.

Calcinaro F, Dionisi S, Marinaro M, Candeloro P, et al. (2005). Oral probiotic administration induces interleukin-10 production and prevents spontaneous autoimmune diabetes in the non-obese diabetic mouse. Diabetologia 48: 1565-1575. doi:10.1007/s00125-005-1831-2.

Cavanagh D, Guinane CM, Neve H, Coffey A et al. (2014). Phages of non-dairy lactococci: isolation and characterization of $\Phi \mathrm{L} 47$, a phage infecting the grass isolate Lactococcus lactis ssp. cremoris DPC6860. Front. Microbiol. 4: 1-15. doi:10.3389/fmicb.2013.00417.

Chae CS, Kwon H-K, Hwang J-S, Kim J-E, et al. (2012). Prophylactic Effect of Probiotics on the Development of Experimental Autoimmune Myasthenia Gravis. PLoS One. 7: e52119. doi:10.1371/journal.pone.0052119.

Chaillou S, Champomier-Vergè .-C, Cornet M, Crutz-Le Coq A-M, et al. (2005). The complete genome sequence of the meat-borne lactic acid bacterium Lactobacillus sakei. 23K. doi:10.1038/nbt1160.

Chauviere G, Coconnier M-H, Kerneis S, Fourniat J, et al. (1992). Adhesion of human Lactobacillus acidophilus strain LB to human enterocyte-like Caco-2 cells. J. Gen. Microbiol. 138: 1689-1696. doi:10.1099/00221287-138-8-1689. 
Colliou N, Ge Y, Sahay B, Gong M, et al. (2017). Commensal Propionibacterium strain UF1 mitigates intestinal inflammation via Th17 cell regulation. J. Clin. Invest. 127: 3970-3986. doi:10.1172/JCI95376.

Corcoran B, Stanton C, Fitzgerald G and Ross R (2008). Life Under Stress: The Probiotic Stress Response and How it may be Manipulated. Curr. Pharm. Des. doi:10.2174/138161208784480225.

Cotter PD, Hill C and Ross RP (2005). Bacteriocins: developing innate immunity for food. Nat. Rev. Microbiol. 3: 777 788. doi:10.1038/nrmicro1273.

Cousin FJ, Jouan-Lanhouet S, Théret N, Brenner C, et al. (2016). The probiotic Propionibacterium freudenreichii as a new adjuvant for TRAIL-based therapy in colorectal cancer. Oncotarget. 7: 7161-7178. doi:10.18632/oncotarget.6881.

Crawley AB and Barrangou R (2018). Conserved Genome Organization and Core Transcriptome of the Lactobacillus acidophilus Complex. Front. Microbiol. 9: 1834. doi:10.3389/fmicb.2018.01834.

Cronin M, Ventura M, Fitzgerald GF and Van Sinderen D (2011). Progress in genomics, metabolism and biotechnology of bifidobacteria. Int. J. Food Microbiol. 149: 4-18. doi:10.1016/j.ijfoodmicro.2011.01.019.

David PR, Berger B, Desiere F, Vilanova D, et al. (2004). The genome sequence of the probiotic intestinal bacterium Lactobacillus johnsonii NCC 533. PNAS 101: 2512-2517. Available at: www.ncbi.nlm.nih.govTaxonomy [Accessed July 31, 2019].

De La Plaza M, Fernández De Palencia P, Peláez C, et al. (2004). Biochemical and molecular characterization of $\alpha$ ketoisovalerate decarboxylase, an enzyme involved in the formation of aldehydes from amino acids by Lactococcus lactis. FEMS Microbiol. Lett. 238: 367-374. doi:10.1016/j.femsle.2004.07.057.

de Moreno de LeBlanc A, del Carmen S, Zurita-Turk M, Santos Rocha C, et al. (2011). Importance of IL-10 Modulation by Probiotic Microorganisms in Gastrointestinal Inflammatory Diseases. ISRN Gastroenterol. 2011: 892971. doi:10.5402/2011/892971.

Denou E, Pridmore RD, Berger B, Panoff JM, et al. (2008). Identification of genes associated with the long-gutpersistence phenotype of the probiotic Lactobacillus johnsonii strain NCC533 using a combination of genomics and transcriptome analysis. J. Bacteriol. 190: 3161-3168. doi:10.1128/JB.01637-07.

Deutsch S-M, Mariadassou M, Nicolas P, Parayre S, et al. (2017). Identification of proteins involved in the antiinflammatory properties of Propionibacterium freudenreichii by means of a multi-strain study. Sci. Rep. 7: 46409. doi:10.1038/srep46409.

Deutsch, S., Mariadassou, M., Díaz-Muñiz I, Banavara DS, Budinich MF, Rankin AS, et al. (2006). Lactobacillus casei metabolic potential to utilize citrate as an energy source in ripening cheese: A bioinformatics approach. J. Appl. Microbiol. 101: 872-882. doi:10.1111/j.1365-2672.2006.02965.x.

Dickson RP, Erb-Downward JR and Huffnagle GB (2013). The role of the bacterial microbiome in lung disease. Expert Rev. Respir. Med. 7: 245-257. doi:10.1586/ers.13.24.

Didelot X, Bowden R, Wilson DJ, Peto TEA, et al. (2012). Transforming clinical microbiology with bacterial genome sequencing. Nat. Rev. Genet. 13: 601-612. doi:10.1038/nrg3226.

Dinan TG and Cryan JF (2017). Microbes, Immunity and Behavior: Psychoneuroimmunology Meets the Microbiome. Neuropsychopharmacology. 42: 178-192. doi:10.1038/npp.2016.103.

do Carmo FLR, Rabah H, Huang S, Gaucher F, et al. (2017). Propionibacterium freudenreichii Surface Protein SlpB Is Involved in Adhesion to Intestinal HT-29 Cells. Front. Microbiol. 8: 1033. doi:10.3389/fmicb.2017.01033.

do Carmo FLR, Silva WM, Tavares GC, Ibraim IC, et al. (2018). Mutation of the Surface Layer Protein SlpB Has Pleiotropic Effects in the Probiotic Propionibacterium freudenreichii CIRM-BIA 129. Front. Microbiol. 9: 1807. doi:10.3389/fmicb.2018.01807.

Douillard P, Ribbera A, Järvinen HM, Kant R, et al. (2013). Comparative Genomic and Functional Analysis of Lactobacillus casei and Lactobacillus rhamnosus Strains Marketed as Probiotics. Appl. Environ. Microbiol. 79: 1923-1933. doi:10.1128/AEM.03467-12.

Duan J, Chung H, Troy E and Kasper DL (2010). Microbial Colonization Drives Expansion of IL-1 Receptor 1Expressing and IL-17-Producing $\gamma / \delta$ T Cells. Cell Host Microbe. 7: 140-150. doi:10.1016/j.chom.2010.01.005.

Dubourg G, Lagier JC, Robert C, Armougom F, et al. (2014). Culturomics and pyrosequencing evidence of the reduction in gut microbiota diversity in patients with broad-spectrum antibiotics. Int. J. Antimicrob. Agents 44: 117-124. doi:10.1016/j.ijantimicag.2014.04.020.

Dunn WB and Ellis DI (2005). Metabolomics: Current Analytical Platforms and Methodologies. Trends Anal Chem. 24: 285-294. doi: 10.1016/j.trac.2004.11.021

Foligné B, Daniel C and Pot B (2013). Probiotics from research to market: the possibilities, risks and challenges. Curr. Opin. Microbiol. 16: 284-292. doi:10.1016/j.mib.2013.06.008.

Foligné B, Deutsch S-M, Breton J, Cousin FJ, et al. (2010). Promising immunomodulatory effects of selected strains of dairy propionibacteria as evidenced in vitro and in vivo. Appl. Environ. Microbiol. 76: 8259-64. doi:10.1128/AEM.01976-10.

Francino M (2014). Early Development of the Gut Microbiota and Immune Health. Pathogens. 3: 769-790. doi:10.3390/pathogens3030769.

Frei R, Akdis M and O'Mahony L (2015). Prebiotics, probiotics, synbiotics, and the immune system. Curr. Opin. Gastroenterol. 31: 153-158. doi:10.1097/MOG.0000000000000151.

Genetics and Molecular Research 19 (2): gmr18599 
Gagnaire V, Jardin J, Rabah H, Briard-Bion V, et al. (2015). Emmental Cheese Environment Enhances Propionibacterium freudenreichii Stress Tolerance. PLoS One. 10: e0135780. doi:10.1371/journal.pone.0135780.

Gallo RL and Hooper LV (2012). Epithelial antimicrobial defence of the skin and intestine. Nat. Rev. Immunol. 12: 503516. doi:10.1038/nri3228.

Garneau JE and Moineau S (2011). Bacteriophages of lactic acid bacteria and their impact on milk fermentations. Microb. Cell Fact. 10: S20. doi:10.1186/1475-2859-10-S1-S20.

Gandhi A and Shah NP (2017). Integrating Omics to Unravel the Stress-Response Mechanisms in Probiotic Bacteria: Approaches, Challenges, and Prospects. Crit Rev Food Sci 57: 3464-3471. doi: 10.1080/10408398.2015.1136805.

Gilad O, Svensson B, Viborg AH, Stuer-Lauridsen B, et al. (2011). The extracellular proteome of Bifidobacterium animalis subsp. lactis BB-12 reveals proteins with putative roles in probiotic effects. Proteomics. 11: 2503-2514. doi:10.1002/pmic.201000716.

Goh YJ and Klaenhammer TR (2010). Functional roles of aggregation-promoting-like factor in stress tolerance and adherence of Lactobacillus acidophilus NCFM. Appl. Environ. Microbiol. 76: 5005-5012. doi:10.1128/AEM.00030-10.

Gratia A (1925). Sur un remarquable exemple d'antagonisme entre deux souches de colibacille. Compt. Rend. Soc. Biol 93: $1040-1042$

Hamon E, Horvatovich P, Izquierdo E, Bringel F, et al. (2011). Comparative proteomic analysis of Lactobacillus plantarum for the identification of key proteins in bile tolerance. BMC Microbiol. 11: 63. doi:10.1186/1471-218011-63.

Handelsman J (2005). Metagenomics: Application of Genomics to Uncultured Microorganisms. Microbiol. Mol. Biol. Rev. 69: 195-195. doi:10.1128/MMBR.69.1.195.2005.

Handelsmanl J, Rondon' MR, Brady SF, Clardy J, et al. (1998). Molecular biological access to the chemistry of unknown 05SP 09 soil microbes: a new frontier for natural products E4 + qfs. Chem. Biol. 5: 245-249. Available at: http://biomednet.com/elecref/10745521005R0245 [Accessed July 31, 2019].

Harris HMB, Bourin MJB, Claesson MJ and O'Toole PW (2017). Phylogenomics and comparative genomics of Lactobacillus salivarius, a mammalian gut commensal. Microb. Genomics. 3: 1-16. doi:10.1099/mgen.0.000115.

$\mathrm{He} \mathrm{F}$, Ouwehand AC, Hashimoto H, Isolauri E, et al. (2001). Adhesion of Bifidobacterium spp. to human intestinal mucus. Microbiol. Immunol. 45: 259-262. doi:10.1111/j.1348-0421.2001.tb02615.x.

Hill DA and Artis D (2010). Intestinal Bacteria and the Regulation of Immune Cell Homeostasis. Annu. Rev. Immunol. 28: 623-667. doi:10.1146/annurev-immunol-030409-101330.

Hirsch A, Grinsted E, Chapman HR and Mattick ATR (1951). A note on the inhibition of an anaerobic sporeformer in Swiss-type cheese by a nisin-producing streptococcus. J. Dairy Res. 18: 205-206. doi:10.1017/S0022029900006075.

Hong Y-H, Nishimura Y, Hishikawa D, Tsuzuki H, et al. (2005). Acetate and Propionate Short Chain Fatty Acids Stimulate Adipogenesis via GPCR43. Endocrinology. 146: 5092-5099. doi:10.1210/en.2005-0545.

Hosono A (1992). Fermented milk in the orient. In: Naga Sawa, Y., Hosono, A. (Eds.), Functions of fermented milk. Challenges for the health sciences. Elsevier Applied Science. pp. 61-78.

Howell TH (1988). Metchnikoff and prolongation of life. Age Ageing 17: 420-421. doi:10.1093/ageing/17.6.420.

Huang DW, Sherman BT and Lempicki RA (2009). Bioinformatics Enrichment Tools: Paths toward the Comprehensive Functional Analysis of Large Gene Lists. Nucleic Acids Res. 37: 1-13. doi:10.1093/nar/gkn923.

Hugon P, Dufour JC, Colson P, Fournier PE, et al. (2015). A comprehensive repertoire of prokaryotic species identified in human beings. Lancet Infect. Dis. 15: 1211-1219. doi:10.1016/S1473-3099(15)00293-5.

Jack RW, Tagg JR and Ray B (1995). Bacteriocins of Gram-Positive Bacteria. Microbiol. Rev. 59: 171-200. Available at: https://www.ncbi.nlm.nih.gov/pmc/articles/PMC239359/pdf/590171.pdf [Accessed July 31, 2019].

Jan G, Belzacq A-S, Haouzi D, Rouault A, et al. (2002). Propionibacteria induce apoptosis of colorectal carcinoma cells via short-chain fatty acids acting on mitochondria. Cell Death Differ. 9: 179-188. doi:10.1038/sj.cdd.4400935.

Jan G, Leverrier P, Pichereau V and Boyaval P (2001). Changes in Protein Synthesis and Morphology during Acid Adaptation of Propionibacterium freudenreichii. Appl. Environ. Microbiol. 67: 2029-2036. doi:10.1128/AEM.67.5.2029-2036.2001.

Janik R, Thomason LAM, Stanisz AM, Forsythe P, et al. (2016). Magnetic resonance spectroscopy reveals oral Lactobacillus promotion of increases in brain GABA, N-acetyl aspartate and glutamate. Neuroimage. 125: 988-995. doi:10.1016/j.neuroimage.2015.11.018.

Jiménez-Pranteda ML, Pérez-Davó A, Monteoliva-Sánchez M, Ramos-Cormenzana A, et al. (2015). Food Omics Validation: Towards Understanding Key Features for Gut Microbiota, Probiotics and Human Health. Food Analytical Methods. 8: 272-289. (2). doi:10.1007/s12161-014-9923-6.

Johnson BR and Klaenhammer TR (2014). Impact of genomics on the field of probiotic research: historical perspectives to modern paradigms. Anto Leeuw Int. J. G. 106: 141-156. doi:10.1007/s10482-014-0171-y.

Kabat AM, Srinivasan N and Maloy KJ (2014). Modulation of immune development and function by intestinal microbiota. Trends Immunol. 35: 507-517. doi:10.1016/j.it.2014.07.010.

Kang H-J and Im S-H (2015). Probiotics as an Immune Modulator. J. Nutr. Sci. Vitaminol. (Tokyo). 61: S103-S105. doi:10.3177/jnsv.61.S103.

Genetics and Molecular Research 19 (2): gmr18599 
Kankainen M, Paulin L, Tynkkynen S, von Ossowski I, et al. (2009). Comparative genomic analysis of Lactobacillus rhamnosus GG reveals pili containing a human- mucus binding protein. Proc. Natl. Acad. Sci. 106: 17193-17198. doi:10.1073/pnas.0908876106.

Kapse NG, Engineer AS, Gowdaman V, Wagh S, et al. (2018). Functional annotation of the genome unravels probiotic potential of Bacillus coagulans HS243. Genomics. 111: 921-929. doi:10.1016/j.ygeno.2018.05.022.

Karpiński TM and Szkaradkiewicz AK (2013). Characteristic of bacteriocines and their application. Polish J. Microbiol. 62: 223-235.

Khalid K (2011). An overview of lactic acid bacteria. Int. J. Biosci. 1: 1-13.

Klaenhammer T (1993). Genetics of bacteriocins produced by lactic acid bacteria. FEMS Microbiol. Rev. 12: 39-85. doi:10.1016/0168-6445(93)90057-G.

Klaenhammer T, Altermann E, Arigoni F, Bolotin A, et al. (2002). Discovering lactic acid bacteria by genomics. Anto Leeuw Int. J. G. 82: 29-58. doi:10.1023/A:1020638309912.

Klaenhammer TR, Kleerebezem M, Kopp MV and Rescigno M (2012). The impact of probiotics and prebiotics on the immune system. Nat. Rev. Immunol. 12: 728-734. doi:10.1038/nri3312.

Kleerebezem M, Boekhorst J, van Kranenburg R, Molenaar D, et al. (2003). Complete genome sequence of Lactobacillus plantarum WCFS1. Proc. Natl. Acad. Sci. 100: 1990-1995. doi:10.1073/pnas.0337704100.

Konstantinov SR, Smidt H, de Vos WM, Bruijn, SCM, et al. (2008). S layer protein A of Lactobacillus acidophilus NCFM regulates immature dendritic cell and T cell functions. Proc. Natl. Acad. Sci. 105: 19474-19479. doi:10.1073/pnas.0810305105.

Konuray G and Erginkaya Z (2018). Potential Use of Bacillus coagulans in the Food Industry. Foods. 7: 92. doi:10.3390/foods7060092.

Koskenniemi K, Laakso K, Koponen J, Kankainen M, et al. (2011). Proteomics and Transcriptomics Characterization of Bile Stress Response in Probiotic Lactobacillus rhamnosus GG. Mol. Cell. Proteomics. 10: M110.002741. doi:10.1074/mcp.M110.002741.

La Fata G, Weber P and Mohajeri MH (2018). Probiotics and the Gut Immune System: Indirect Regulation. Probiotics Antimicrob. Proteins. 10: 11-21. doi:10.1007/s12602-017-9322-6.

Lagier J-C, Dubourg G, Million M, Cadoret F, et al. (2018). Culturing the human microbiota and culturomics. Nat. Rev. Microbiol. 16: 540-550. doi:10.1038/s41579-018-0041-0.

Lagier J-C, Khelaifia S, Alou MT, Ndongo S, et al. (2016). Culture of previously uncultured members of the human gut microbiota by culturomics. Nat. Microbiol. 1: 16203. doi:10.1038/nmicrobiol.2016.203.

Lagier JC, Armougom F, Million M, Hugon P, et al. (2012). Microbial culturomics: Paradigm shift in the human gut microbiome study. Clin. Microbiol. Infect. 18: 1185-1193. doi:10.1111/1469-0691.12023.

Lan A, Bruneau A, Bensaada M, Philippe C, et al. (2008). Increased induction of apoptosis by Propionibacterium freudenreichii TL133 in colonic mucosal crypts of human microbiota-associated rats treated with 1,2dimethylhydrazine. Br. J. Nutr. 100: 1251-1259. doi:10.1017/S0007114508978284.

Lavasani S, Dzhambazov B, Nouri M, Fåk F, et al. (2010). A Novel Probiotic Mixture Exerts a Therapeutic Effect on Experimental Autoimmune Encephalomyelitis Mediated by IL-10 Producing Regulatory T Cells. PLoS One. 5: e9009. doi:10.1371/journal.pone.0009009.

Le Maréchal C, Peton V, Plé C, Vroland C, et al. (2015). Surface proteins of Propionibacterium freudenreichii are involved in its anti-inflammatory properties. J. Proteomics. 113: 447-461. doi:10.1016/j.jprot.2014.07.018.

Lebeer S, Claes IJJ, Verhoeven TLA, Shen C, et al. (2008). Impact of luxS and Suppressor Mutations on the Gastrointestinal Transit of Lactobacillus rhamnosus GG. Appl. Environ. Microbiol. 74: 4711-4718. doi:10.1128/AEM.00133-08.

Lebeer S, Vanderleyden J and De Keersmaecker SCJ (2010). Host interactions of probiotic bacterial surface molecules: Comparison with commensals and pathogens. Nat. Rev. Microbiol. 8: 171-184. doi:10.1038/nrmicro2297.

Lee E-S, Song E-J, Nam Y-D and Lee S-Y (2018). Probiotics in human health and disease: from nutribiotics to pharmabiotics. J. Microbiol. 56: 773-782. doi:10.1007/s12275-018-8293-y.

Leverrier P, Dimova D, Pichereau V, Auffray Y, et al. (2003). Susceptibility and Adaptive Response to Bile Salts in Propionibacterium freudenreichii: Physiological and Proteomic Analysis. Appl. Environ. Microbiol. 69: 38093818. doi:10.1128/AEM.69.7.3809-3818.2003.

Leverrier P, Vissers JPC, Rouault A, Boyaval P, et al. (2004). Mass spectrometry proteomic analysis of stress adaptation reveals both common and distinct response pathways in Propionibacterium freudenreichii. Arch. Microbiol. 181: 215-230. doi:10.1007/s00203-003-0646-0.

Li P, Li X, Gu Q, Lou X-Y, et al. (2016). Comparative genomic analysis of Lactobacillus plantarum ZJ316 reveals its genetic adaptation and potential probiotic profiles. J Zhejiang Univ-Sci B (Biomed Biotechnol) 17: 569-579. doi:10.1631/jzus.

Llewellyn A and Foey A (2017). Probiotic Modulation of Innate Cell Pathogen Sensing and Signaling Events. Nutrients. 9: 1156. doi:10.3390/nu9101156.

McFarland LV (2014). Use of probiotics to correct dysbiosis of normal microbiota following disease or disruptive events: a systematic review. BMJ Open. 4: e005047-e005047. doi:10.1136/bmjopen-2014-005047. 
Medina V, Edmonds B, Young GP, James R, et al. (1997). Induction of caspase-3 protease activity and apoptosis by butyrate and trichostatin a (Inhibitors of histone deacetylase): Dependence on protein synthesis and synergy with a mitochondrial/cytochrome c-dependent pathway. Cancer Res. 57: 3697-3707.

Moineau S and Lévesque C (2004). "Control of Bacteriophages in Industrial Fermentations," in Bacteriophages Biology and Applications, ed. A. S. Elizabeth Kutter (CRC press), 1-12.

Mozzi F, Ortiz ME, Bleckwedel J, De Vuyst L, et al. (2013). Metabolomics as a tool for the comprehensive understanding of fermented and functional foods with lactic acid bacteria. Food Res. Int. 54: 1152-1161. doi:10.1016/j.foodres.2012.11.010.

Nobutani K, Sawada D, Fujiwara S, Kuwano Y, et al. (2017). The effects of administration of the Lactobacillus gasseri strain CP2305 on quality of life, clinical symptoms and changes in gene expression in patients with irritable bowel syndrome. J. Appl. Microbiol. 122: 212-224. doi:10.1111/jam.13329.

O'Flaherty S and Klaenhammer TR (2010). The role and potential of probiotic bacteria in the gut, and the communication between gut microflora and gut/host. Int. Dairy J. 20: 262-268. doi:10.1016/j.idairyj.2009.11.011.

Oliveira LC, Saraiva TDL, Silva WM, Pereira UP, et al. (2017). Analyses of the probiotic property and stress resistancerelated genes of Lactococcus lactis subsp. lactis NCDO 2118 through comparative genomics and in vitro assays. PLoS One. 12: e 0175116. doi:10.1371/journal.pone.0175116.

Ouwehand AC, Salminen S and Isolauri E (2002). Probiotics an overview of beneficial effects. Anto Leeuw Int. J. G. 82: 279-289.

Papadimitriou K, Zoumpopoulou G, Foligné B, Alexandraki V, et al. (2015). Discovering probiotic microorganisms: in vitro, in vivo, genetic and omics approaches. Front Microbiol. 6: 58. doi:10.3389/fmicb.2015.00058.

Perakakis N, Yazdani A, Karniadakis GE and Mantzoros C (2018). Omics, Big Data and Machine Learning as Tools to Propel Understanding of Biological Mechanisms and to Discover Novel Diagnostics and Therapeutics. Metabolism. 87: A1-A9. doi: https://doi.org/10.1016/j.metabol.2018.08.002

Pfeiler EA and Klaenhammer TR (2007). The genomics of lactic acid bacteria. Trends Microbiol. 15: 546-553. doi:10.1016/j.tim.2007.09.010.

Pfleiderer A, Lagier JC, Armougom F, Robert C, et al. (2013). Culturomics identified 11 new bacterial species from a single anorexia nervosa stool sample. Eur. J. Clin. Microbiol. Infect. Dis. 32: 1471-1481. doi:10.1007/s10096-013$1900-2$.

Porter CK, Gormley R, Tribble DR, Cash BD, et al. (2011). The Incidence and Gastrointestinal Infectious Risk of Functional Gastrointestinal Disorders in a Healthy US Adult Population. Am. J. Gastroenterol. 106: 130-138. doi:10.1038/ajg.2010.371.

Round JL and Mazmanian SK (2009). The gut microbiota shapes intestinal immune responses during health and disease. Nat. Rev. Immunol. 9: 313-323. doi:10.1038/nri2515.

Russo P, Mohedano M de la L, Capozzi V, de Palencia PF, et al. (2012). Comparative proteomic analysis of Lactobacillus plantarum WCFS1 and $\Delta$ ctsR mutant strains under physiological and heat stress conditions. Int. J. Mol. Sci. 13: 10680-10696. doi:10.3390/ijms130910680.

Salminen S, von Wright A, Morelli L, Marteau P, et al. (1998). Demonstration of safety of probiotics - a review. Int. J. Food Microbiol. 44: 93-106. doi:10.1016/S0168-1605(98)00128-7.

Salque M, Bogucki PI, Pyzel J, Sobkowiak-Tabaka I, et al. (2013). Earliest evidence for cheese making in the sixth millennium bc in northern Europe. Nature. 493: 522-525. doi:10.1038/nature11698.

Salvetti E, Harris HMB, Felis GE and O'Toole PW (2018). Comparative genomics reveals robust phylogroups in the genus Lactobacillus as the basis for reclassification. Appl. Environ. Microbiol. 84: e00993-18. doi:10.1128/AEM.00993-18.

Sánchez B, Champomier-Vergè M-C, Anglade P, Baraige F, et al. (2005). Proteomic Analyis of Global Changes in Protein Expression during Bile Salt Exposure of Bifidobacterium longum NCIMB 8809. J. Bacteriol. 187: 57995808. doi:10.1128/JB.187.16.5799-5808.2005.

Sander R (2017). Use of probiotics for infection prevention in trauma patients. Nurs. Older People. 29 : 11. doi:10.7748/nop.29.6.11.s11.

Saraoui T, Parayre S, Guernec G, Loux V, et al. (2013). A unique in vivo experimental approach reveals metabolic adaptation of the probiotic Propionibacterium freudenreichii to the colon environment. BMC Genomics. 14: 911. doi:10.1186/1471-2164-14-911.

Saulnier DM, Santos F, Roos S, Mistretta T-A, et al. (2011). Exploring Metabolic Pathway Reconstruction and GenomeWide Expression Profiling in Lactobacillus reuteri to Define Functional Probiotic Features. PLoS One. 6: e18783. doi:10.1371/journal.pone.0018783.

Schmidt H and Hensel M (2004). Pathogenicity islands in bacterial pathogenesis. Clin. Microbiol. Rev. 17: 14-56. doi:10.1128/CMR.17.1.14.

Senan S, Prajapati JB and Joshi CG (2014). Comparative genome-scale analysis of niche-based stress-responsive genes in Lactobacillus helveticus strains. Genome. 57: 185-192. doi:10.1139/gen-2014-0020.

Senan S, Prajapati JB and Joshi CG (2015). Feasibility of Genome-Wide Screening for Biosafety Assessment of Probiotics: A Case Study of Lactobacillus helveticus MTCC 5463. Probiotics Antimicrob. Proteins. 7: 249-258. doi:10.1007/s12602-015-9199-1.

Genetics and Molecular Research 19 (2): gmr18599 
Sharma M and Shukla G (2016). Metabiotics: One Step ahead of Probiotics; an Insight into Mechanisms Involved in Anticancerous Effect in Colorectal Cancer. Front. Microbiol. 7: 1940. doi:10.3389/fmicb.2016.01940.

Shen Y-HA and Nahas R (2009). Complementary and alternative medicine for treatment of irritable bowel syndrome. Can. Fam. physician Médecin Fam. Can. 55: 143-8. doi:10.3969/j.issn.1008-7125.2012.08.014.

Shenderov BA (2013). Metabiotics: novel idea or natural development of probiotic conception. Microb. Ecol. Heal. Dis. 24: 10.3402. doi:10.3402/mehd.v24i0.20399.

Shortt C. (1999). The probiotic century: Historical and current perspectives. Trends Food Sci. Technol. 10: 411-417. doi:10.1016/S0924-2244(00)00035-2.

Smeianov VV, Wechter P, Broadbent JR, Hughes JE, et al. (2007). Comparative High-Density Microarray Analysis of Gene Expression during Growth of Lactobacillus helveticus in Milk versus Rich Culture Medium. Appl. Environ. Microbiol. 73: 2661-2672. doi:10.1128/AEM.00005-07.

Smit BA, van Hylckama Vlieg JET, Engels WJM, Meijer L, et al. (2005). Identification, Cloning, and Characterization of a Lactococcus lactis Branched-Chain -Keto Acid Decarboxylase Involved in Flavor Formation. Appl. Environ. Microbiol. 71: 303-311. doi:10.1128/AEM.71.1.303-311.2005.

So J-S, Kwon H-K, Lee C-G, Yi H-J, et al. (2008). Lactobacillus casei suppresses experimental arthritis by downregulating T helper 1 effector functions. Mol. Immunol. 45: 2690-2699. doi:10.1016/j.molimm.2007.12.010.

Soares SDC, Luiz A, Thiago R, Ramos J, et al. (2011). Plasticidade Genômica e Evolução Bacteriana. Microbiol. Foco 4: 31-38.

Sood A, Midha V, Makharia GK, Ahuja V, et al. (2009). The Probiotic Preparation, VSL\#3 Induces Remission in Patients With Mild-to-Moderately Active Ulcerative Colitis. Clin. Gastroenterol. Hepatol. 7: 1202-1209.e1. doi:10.1016/j.cgh.2009.07.016.

Soto GE and Hultgren SJ (1999). Bacterial Adhesins : Common Themes and Variations in Architecture and Assembly MINIREVIEW Bacterial Adhesins: Common Themes and Variations in Architecture and Assembly. 181: 10591071.

Sugahara H, Odamaki T, Fukuda S, Kato T, et al. (2015). Probiotic Bifidobacterium longum alters gut luminal metabolism through modification of the gut microbial community. Sci. Rep. 5: 13548. doi:10.1038/srep13548.

Summers WC (2005). "Bacteriophage Research: Early History," in Bacteriophages Biology and Applications, eds. E. Kutter and A. Sulakvelidze (New Haven: CRC press), 1-485.

Sybesma W, Molenaar D, van IJcken W, Venema K, et al. (2013). Genome Instability in Lactobacillus rhamnosus GG. Appl. Environ. Microbiol. 79: 2233-2239. doi:10.1128/AEM.03566-12.

Tidjani Alou M, Million M, Traore SI, Mouelhi D, et al. (2017). Gut Bacteria Missing in Severe Acute Malnutrition, Can We Identify Potential Probiotics by Culturomics? Front. Microbiol. 8: 899. doi:10.3389/fmicb.2017.00899.

Tuomola EM and Salminen SJ (1998). Adhesion of some probiotic and dairy Lactobacillus strains to Caco-2 cell cultures. Int. J. Food Microbiol. 41: 45-51. doi:10.1016/S0168-1605(98)00033-6.

Turnbaugh PJ, Ley RE, Mahowald MA, Magrini V, et al. (2006). An obesity-associated gut microbiome with increased capacity for energy harvest. Nature. 444: 1027-1031. doi:10.1038/nature05414.

Tursi A, Brandimarte G, Papa A, Giglio A, et al. (2010). Treatment of Relapsing Mild-to-Moderate Ulcerative Colitis With the Probiotic VSL\#3 as Adjunctive to a Standard Pharmaceutical Treatment: A Double-Blind, Randomized, Placebo-Controlled Study. Am. J. Gastroenterol. 105: 2218-2227. doi:10.1038/ajg.2010.218.

Umu ÖCO, Bäuerl C, Oostindjer M, Pope PB, et al. (2016). The Potential of Class II Bacteriocins to Modify Gut Microbiota to Improve Host Health. PLoS One. 11: e0164036. doi:10.1371/journal.pone.0164036.

van Baarlen P, Troost F, van der Meer C, Hooiveld G, et al. (2011). Human mucosal in vivo transcriptome responses to three lactobacilli indicate how probiotics may modulate human cellular pathways. Proc. Natl. Acad. Sci. 108: $4562-$ 4569. doi:10.1073/pnas.1000079107.

van Belkum MJ and Stiles ME (2000). Nonlantibiotic antibacterial peptides from lactic acid bacteria. Nat. Prod. Rep. 17: 323-335. doi:10.1039/a801347k.

Van de Guchte M, Ehrlich SD and Maguin E (2001). Production of growth-inhibiting factors by Lactobacillus delbrueckii. J. Appl. Microbiol. 91: 147-153. doi:10.1046/j.1365-2672.2001.01369.x.

van der Meulen SB, de Jong A and Kok J (2016). Transcriptome landscape of Lactococcus lactis reveals many novel RNAs including a small regulatory RNA involved in carbon uptake and metabolism. RNA Biol. 13: 353-366. doi:10.1080/15476286.2016.1146855.

Vélez MP, De Keersmaecker SCJ and Vanderleyden J (2007). Adherence factors of Lactobacillus in the human gastrointestinal tract. FEMS Microbiol. Lett. 276: 140-148. doi:10.1111/j.1574-6968.2007.00908.x.

Venter JC (2004). Environmental Genome Shotgun Sequencing of the Sargasso Sea. Science. 304: 66-74. doi:10.1126/science.1093857.

Verma A and Shukla G (2013). Administration of prebiotic inulin suppresses 1,2 dimethylhydrazine dihydrochloride induced procarcinogenic biomarkers fecal enzymes and preneoplastic lesions in early colon carcinogenesis in Sprague Dawley rats. J. Funct. Foods. 5: 991-996. doi:10.1016/j.jff.2013.02.006.

Viljanen M, Pohjavuori E, Haahtela T, Korpela R et al. (2005). Induction of inflammation as a possible mechanism of probiotic effect in atopic eczema-dermatitis syndrome. J. Allergy Clin. Immunol. 115: 1254-1259. doi:10.1016/j.jaci.2005.03.047. 
Weiss G and Jespersen L (2010). Transcriptional Analysis of Genes Associated with Stress and Adhesion in Lactobacillus acidophilus NCFM during the Passage through an in vitro Gastrointestinal Tract Model. J. Mol. Microbiol. Biotechnol. 18: 206-214. doi:10.1159/000316421.

Westfall S, Lomis N, Kahouli I, Dia SY, et al. (2017). Microbiome, probiotics and neurodegenerative diseases: deciphering the gut brain axis. Cell. Mol. Life Sci. 74: 3769-3787. doi:10.1007/s00018-017-2550-9.

Wommack KE and Colwell RR (2000). Virioplankton: viruses in aquatic ecosystems. Microbiol. Mol. Biol. Rev. 64: 69114. Available at: http://www.ncbi.nlm.nih.gov/pubmed/10704475 [Accessed July 30, 2019].

Yang J, Ji Y, Park H, Lee J, et al. (2014). Selection of functional lactic acid bacteria as starter cultures for the fermentation of Korean leek (Allium tuberosum Rottler ex Sprengel.). Int. J. Food Microbiol. 191: 164-171. doi:10.1016/j.jijfoodmicro.2014.09.016.

Yuan J, Wang B, Sun Z, Bo X, et al. (2008). Analysis of Host-Inducing Proteome Changes in Bifidobacterium longum NCC2705 Grown in Vivo. J. Proteome Res. 7: 375-385. doi:10.1021/pr0704940.

Zheng J, Wittouck S, Salvetti E, Franz CMAP, et al. (2020). A taxonomic note on the genus Lactobacillus: Description of 23 novel genera, emended description of the genus Lactobacillus Beijerinck 1901, and union of Lactobacillaceae and Leuconostocaceae. Int. J. Syst. Evol. Microbiol. 70: 10.1099. doi:10.1099/ijsem.0.004107

Zhong L, Zhang X and Covasa M (2014). Emerging roles of lactic acid bacteria in protection against colorectal cancer. World J. Gastroenterol. 20: 7878. doi:10.3748/wjg.v20.i24.7878. 